\title{
Simulating last interglacial climate with NorESM: role of insolation and greenhouse gases in the timing of peak warmth
}

\author{
P. M. Langebroek ${ }^{1}$ and K. H. Nisancioglu ${ }^{1,2,3}$ \\ ${ }^{1}$ Bjerknes Centre for Climate Research, Uni Research Climate, Allégaten 55, 5007 Bergen, Norway \\ ${ }^{2}$ Department of Earth Science, University of Bergen, Allégaten 41, 5007 Bergen, Norway \\ ${ }^{3}$ Bjerknes Centre for Climate Research, Bergen, Norway \\ Correspondence to: P. M. Langebroek (petra.langebroek@uni.no)
}

Received: 15 July 2013 - Published in Clim. Past Discuss.: 7 August 2013

Revised: 20 May 2014 - Accepted: 3 June 2014 - Published: 10 July 2014

\begin{abstract}
The last interglacial (LIG, 130-116 ka, $\mathrm{ka}=1000 \mathrm{yr}$ ago) is characterized by high-latitude warming and is therefore often considered as a possible analogue for future warming. However, in contrast to predicted future greenhouse warming, the LIG climate is largely governed by variations in insolation. Greenhouse gas (GHG) concentrations were relatively stable and similar to pre-industrial values, with the exception of the early LIG when, on average, GHGs were slightly lower.

We performed six time-slice simulations with the lowresolution version of the Norwegian Earth System Model covering the LIG. In four simulations only the orbital forcing was changed. In two other simulations, representing the early LIG, additionally the GHG forcing was reduced.

With these simulations we investigate (1) the different effects of GHG versus insolation forcing on the temperatures during the LIG; (2) whether reduced GHGs can explain the low temperatures reconstructed for the North Atlantic; and (3) the timing of the observed LIG peak warmth.

Our simulations show that the insolation forcing results in seasonal and hemispheric differences in temperature. In contrast, a reduction in the GHG forcing causes a global and seasonal-independent cooling. Furthermore, we compare modelled temperatures with proxy-based LIG sea-surface temperatures along a transect in the North Atlantic. The modelled North Atlantic summer sea-surface temperatures capture the general trend of the reconstructed summer temperatures, with low values in the early LIG, a peak around $125 \mathrm{ka}$, and a steady decrease towards the end of the LIG. Simulations with reduced GHG forcing improve the model-data fit as they show lower temperatures in the early LIG. Fur-
\end{abstract}

thermore we show that the timing of maximum summer and winter surface temperatures is in line with the local summer and winter insolation maximum at most latitudes. Two regions where the maximum local insolation and temperature do not occur at the same time are Antarctica and the Southern Ocean. The austral summer insolation has a late maximum at $\sim 115 \mathrm{ka}$. In contrast the austral summer temperatures in Antarctica show maxima at both $\sim 130 \mathrm{ka}$ and $\sim 115 \mathrm{ka}$, and the Southern Ocean temperatures peak only at $\sim 130 \mathrm{ka}$. This is probably due to the integrating effect of the ocean, storing heat from other seasons and resulting in relatively warm austral summer temperatures. Reducing the GHG concentrations in the early LIG (125 and $130 \mathrm{ka}$ ) results in a similar timing of peak warmth, except over Antarctica. There, the lower austral summer temperatures at $130 \mathrm{ka}$ shift the maximum warmth to a single peak at $115 \mathrm{ka}$.

\section{Introduction}

The last interglacial period (LIG, $\sim 130-116 \mathrm{ka}, \mathrm{ka}=1000 \mathrm{yr}$ ago) is often considered as an analogue for future climate warming (e.g. Kukla et al., 2002; Jansen et al., 2007; Clark and Huybers, 2009). Indeed, the early LIG is characterized by a warm high-latitude climate (e.g. CAPE Last Interglacial Project Members, 2006), and a global sea level of approximately $7 \mathrm{~m}$ higher than today is found during the LIG (Kopp et al., 2009). However, in contrast to the predicted future greenhouse warming, the climate of the LIG is governed by variations in solar insolation. Atmospheric $\mathrm{CO}_{2}$ concentrations were close to pre-industrial values (Petit et al., 1999; 
Lüthi et al., 2008), as were the other main greenhouse gas (GHG) concentrations (Loulergue et al., 2008; Schilt et al., 2010). Increased GHGs result in a warming in all seasons and regions, whereas changed orbital forcing causes only warming in certain regions and seasons (see Section 3.1).

In addition to numerous studies based on marine proxies (e.g. Leduc et al., 2010; Van Nieuwenhove et al., 2011), a few recent studies have compared reconstructed climate of the LIG to equilibrium simulations with general circulation models (GCMs) (e.g. Born et al., 2011; Govin et al., 2012; Lunt et al., 2013). To first order, simulated and reconstructed LIG mean sea-surface temperatures (SSTs) are comparable and show warm high latitudes, in particular in the North Atlantic. However, for the early part of the LIG $(\sim 130 \mathrm{ka})$ marine proxies show colder conditions in the North Atlantic, Labrador and Norwegian seas compared to model simulations. One possible reason for this is the input of freshwater to the North Atlantic from melting of the remnants of the Saalian ice sheets (penultimate glacial period) (Govin et al., 2012).

On land, Kaspar et al. (2005) compare atmospheric climate model results to palaeobotanically derived European temperatures for $125 \mathrm{ka}$. They find a good match between reconstructed and simulated higher temperatures in the early LIG, and conclude that the different orbital parameters are sufficient to explain the reconstructed patterns over Europe. Lunt et al. (2013) compare LIG temperatures computed by an ensemble of equilibrium climate model simulations to a global temperature reconstruction (sea-surface and land temperatures) compiled by Turney and Jones (2010). They combine a large number of early LIG (between $130 \mathrm{ka}$ and $125 \mathrm{ka}$ ) equilibrium simulations, including this study's $130 \mathrm{ka}$ and $125 \mathrm{ka}$ simulations, and show that the modelled annual mean surface air temperatures over land do not correspond well with the reconstructed LIG temperatures. Comparing simulated summer surface air temperatures to the proxy data set, instead of annual mean, improves the fit, although large discrepancies still exist. In the North Atlantic, the simulated ensemble mean of Lunt et al. (2013) also underestimates the LIG SSTs when compared with marine proxies.

We will go one step further than previous studies by comparing seasonal output from four time-slice simulations to four high-resolution proxy records from the North Atlantic. We focus on the North Atlantic/Nordic Seas because these regions are particularly sensitive to changes in climate forcing and are thought to endure large environmental changes in the near future (e.g. Meehl et al., 2007; Lenton et al., 2008). Also, these records have a relatively high resolution and are all transferred to one common timescale, so no additional errors will be induced when comparing the records to each other. Unfortunately currently no global data set covering the LIG with a high enough resolution (few ka) is available, but work is being done in that direction. After such a data set is reconstructed, a global model-data comparison similar to this North Atlantic comparison can be performed.
Before we discuss the comparison between our simulated temperatures and the LIG proxy records, we will assess the relative effects of GHG and solar insolation forcing on the simulated LIG climate. Finally we will evaluate the timing of peak LIG warmth in our simulations, and document its strong dependence on latitude and whether the locality is over ocean or land.

\section{Methods and experimental set-up}

\subsection{The Norwegian Earth System Model}

We use the Norwegian Earth System Model (NorESM), which is derived from the Community Earth System Model (CESM) developed at the National Center for Atmospheric Research (NCAR). It consists of the same components for the atmosphere (CAM4), land (CLM4) and sea ice (CICE4), and uses the CESM coupler (CLP7). However, a key difference with CESM is the use of a different ocean component, based on the Miami Isopycnic Coordinate Ocean Model (MICOM). This component is largely modified from MICOM in order to improve conservation of mass and heat, and the efficiency and robustness of the transport of tracers (for more details see Assmann et al., 2010).

NorESM participates in the fifth phase of the Climate Model Intercomparison Project (CMIP5; e.g. Taylor et al., 2012). For an in-depth description of NorESM and its climate response to CMIP scenarios, we refer to Bentsen et al. (2013) and Iversen et al. (2013), respectively.

The simulations in this study are performed with the lowresolution version of NorESM (NorESM-L) in order to reduce computation time and allow for several equilibrium simulations. The atmospheric component has a spatial resolution of approximately $3.75^{\circ} \times 3.75^{\circ}$ (T31) and comprises 26 levels in the vertical. The ocean component's horizontal grid size corresponds to a nominal grid size of $3^{\circ}(\mathrm{g} 37)$ and consists of 30 isopycnic layers in the vertical. The sea ice component follows the ocean grid, and the land component follows the atmospheric grid. For further details concerning the different components within NorESM-L and a thorough description of the pre-industrial results, we refer to Zhang et al. (2012).

\subsection{Experimental set-up}

We performed seven time-slice simulations with NorESM-L: one pre-industrial (PI) control experiment and six LIG simulations (see Table 1). All simulations use the modern landsea distribution, topography, ice sheets and vegetation, as constituted in CESM (Vertenstein et al., 2012), as well as modern ocean bathymetry.

In the PI simulation atmospheric GHG concentrations are set to pre-industrial values (see Table 1) and zero levels of chlorofluorocarbons (CFCs). Orbital parameters are set to values for the year 1950 (Berger, 1978). The ocean model is 
Table 1. Scheme of orbital and GHG forcing applied in the PI and LIG simulations. Values follow PMIP3 PI and LIG experimental design. Suffix Gpi refers to greenhouse gas levels $(\mathrm{G})$ at pre-industrial (pi) levels.

\begin{tabular}{lcccccc}
\hline \multirow{2}{*}{ Exp. name } & \multicolumn{3}{c}{ Orbital parameters } & \multicolumn{3}{c}{ Greenhouse gas concentrations } \\
& Ecc & Obl $\left[^{\circ}\right]$ & Peri-180 $\left[^{\circ}\right]$ & $\mathrm{CO}_{2}[\mathrm{ppm}]$ & $\mathrm{CH}_{4}[\mathrm{ppb}]$ & $\mathrm{N}_{2} \mathrm{O}[\mathrm{ppb}]$ \\
\hline PI & 0.0167 & 23.45 & 102.0 & 280 & 760 & 270 \\
115 ka_Gpi & 0.0414 & 22.41 & 110.9 & 280 & 760 & 270 \\
120 ka_Gpi & 0.0411 & 23.01 & 28.0 & 280 & 760 & 270 \\
125 ka_Gpi & 0.0400 & 23.80 & 307.1 & 280 & 760 & 270 \\
125 ka & 0.0400 & 23.80 & 307.1 & 276 & 640 & 263 \\
130 ka_Gpi & 0.0382 & 24.24 & 228.3 & 280 & 760 & 270 \\
130 ka & 0.0382 & 24.24 & 228.3 & 257 & 512 & 239 \\
\hline
\end{tabular}

initialized from modern observed temperatures and salinities (Levitus and Boyer, 1994). While keeping the orbital configuration and GHG fixed, the PI control simulation is run for $1500 \mathrm{yr}$.

The LIG simulations are branched off from the PI simulation at model year 495, when the PI run is close to equilibrium. Four LIG time-slice simulations are performed with fixed pre-industrial GHGs, but with orbital parameters of $115 \mathrm{ka}, 120 \mathrm{ka}, 125 \mathrm{ka}$ and $130 \mathrm{ka}$, respectively. These experiments are given the suffix Gpi in Table 1 denoting greenhouse gas levels $(\mathrm{G})$ at pre-industrial (pi) levels. The two early LIG simulations (125 ka_Gpi and $130 \mathrm{ka}$ _Gpi) are repeated using the lower GHG levels as set by the Paleoclimate Modelling Intercomparison Project 3 (PMIP3) based on Petit et al. (1999); Lüthi et al. (2008); Loulergue et al. (2008) and Schilt et al. (2010) (see $125 \mathrm{ka}$ and $130 \mathrm{ka}$ in Table 1). All LIG simulations are run another $505 \mathrm{yr}$ using the above specified orbital and GHG forcing. Only orbital parameters and GHG concentrations are changed; ozone and aerosols are kept fixed to their pre-industrial values.

All simulations are close to equilibrium in model year 900 . The model results presented in this study are therefore based on the years 901 to 1000 of each simulation. The global mean ocean temperature trend during this final period is found to be small at $0.006-0.024^{\circ} \mathrm{C} / 100 \mathrm{yr}$.

\subsection{Sediment data used for model-data comparison}

We compare the LIG model results to proxy data extracted from four marine sediment cores along a northeastsouthwest transect in the North Atlantic (Table 2). These cores cover the entire period of interest $(130-115 \mathrm{ka})$ and have a relatively high sedimentation rate $(\sim 5$ to $17 \mathrm{~cm} \mathrm{kyr}^{-1}$ ). Govin et al. (2012) transferred these sediment cores to one single timescale based on the Greenland NGRIP $\delta^{18} \mathrm{O}$ ice core record (North Greenland Ice Core Project members, 2004). The total age uncertainty of less than $2500 \mathrm{yr}$ combines uncertainties in the resolution of the records and the procedure transferring all records to a common timescale (Govin et al., 2012). We compare our model results to the reconstructed summer SSTs as provided by
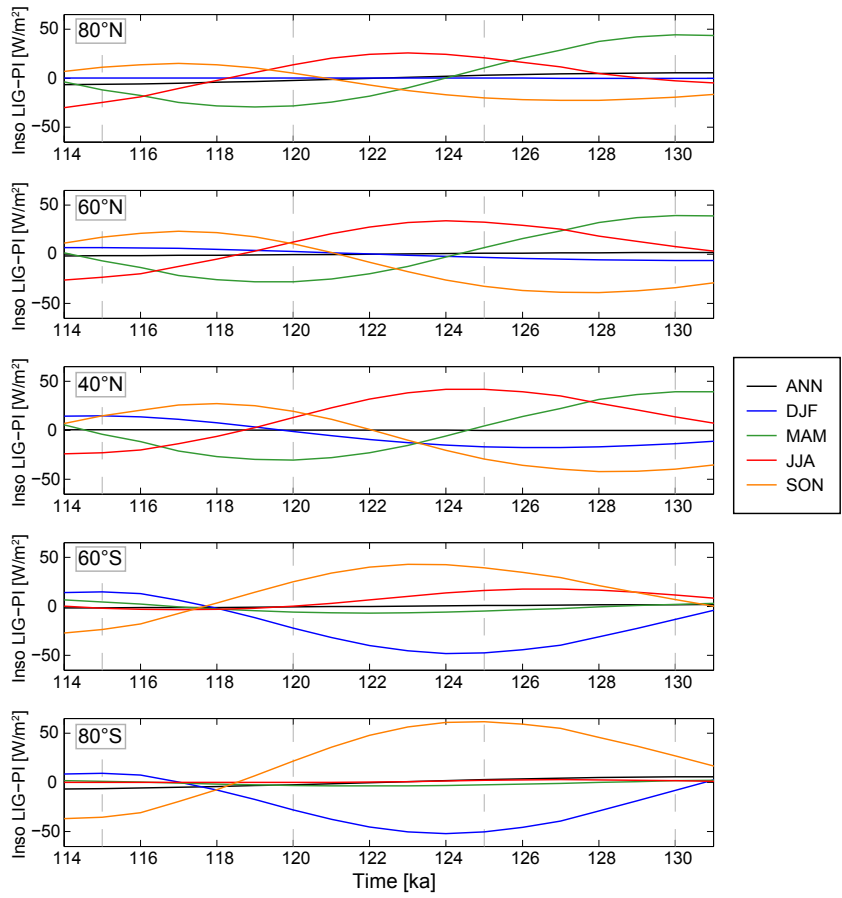

Figure 1. Seasonal mean insolation anomalies for the LIG at different latitudes (80,60 and $40^{\circ} \mathrm{N} ; 60$ and $\left.80^{\circ} \mathrm{S}\right)$. Annual mean (black), DJF (blue), MAM (green), JJA (red) and SON (orange).

Govin et al. (2012), where the SSTs of MD95-2010 and EW9302-JPC2 are reconstructed using the percentage of the polar species Neogloboquadrina pachyderma sinistral, and the SSTs of ODP 980 and CH69-K09 are reconstructed using the modern analogue technique on planktonic foraminifera faunal assemblages. Other proxies (e.g. ice rafted debris, stable isotopes) are not considered in this study, as these are more difficult to compare to the Earth system model output. For a detailed discussion of the sediment core data and dating procedure, we refer to Govin et al. (2012) and the original references in Table 2. 
Table 2. Sediment cores considered in this study.

\begin{tabular}{llrrrl}
\hline Ocean & Core & Latitude & Longitude & Water depth & Reference(s) \\
\hline Norwegian Sea & MD95-2010 & $66.68^{\circ} \mathrm{N}$ & $4.57^{\circ} \mathrm{E}$ & $1226 \mathrm{~m}$ & Risebrobakken et al. (2005, 2006) \\
North Atlantic & ODP 980 & $55.49^{\circ} \mathrm{N}$ & $14.70^{\circ} \mathrm{W}$ & $2168 \mathrm{~m}$ & McManus et al. (1999); Oppo et al. (2006) \\
Labrador Sea & EW9302-JPC2 & $48.80^{\circ} \mathrm{N}$ & $45.09^{\circ} \mathrm{W}$ & $1251 \mathrm{~m}$ & Rasmussen et al. (2003) \\
North Atlantic & CH69-K09 & $41.76^{\circ} \mathrm{N}$ & $47.35^{\circ} \mathrm{W}$ & $4100 \mathrm{~m}$ & Cortijo et al. (1999); Labeyrie et al. (1999)
\end{tabular}

\section{Results and discussion}

\subsection{Simulated seasonal and hemispheric surface air temperatures}

We performed four simulations every $5000 \mathrm{yr}$ covering the LIG by only changing the orbital forcing (115 ka_Gpi, $120 \mathrm{ka} \_\mathrm{Gpi}, 125 \mathrm{ka} \_\mathrm{Gpi}$ and $\left.130 \mathrm{ka} \_\mathrm{Gpi}\right)$. Although the global annual mean incoming insolation is similar for all four runs (less than $3 \mathrm{~W} \mathrm{~m}^{-2}$ different; Fig. 1), their latitudinal and seasonal distribution is significantly different (up to $55 \mathrm{~W} \mathrm{~m}^{-2}$ different from pre-industrial during a specific season and latitude (see below); Fig. 1).

The early LIG (130 ka and $125 \mathrm{ka})$ shows enhanced Northern Hemisphere March-April-May (MAM) insolation compared to pre-industrial conditions (upper three panels in Fig. 1). For 130 ka June-July-August (JJA) insolation is slightly enhanced. Accompanied with reduced Northern Hemisphere December-January-February (DJF) and September-October-November (SON) insolation, this gives a stronger seasonal cycle in the early part of the LIG. The opposite occurs at $115 \mathrm{ka}$, where relatively low Northern Hemisphere JJA and MAM insolation is combined with enhanced SON/DJF insolation, reducing the seasonal insolation contrast. In the Southern Hemisphere (lower two panels in Fig. 1), the early LIG JJA and SON insolation is enhanced, while DJF insolation is reduced. MAM insolation is fairly similar to today. The combined effect is a weak seasonal cycle in the Southern Hemisphere in the early part of the LIG. At $115 \mathrm{ka}$, the Southern Hemisphere seasonal insolation cycle is strengthened due to relatively high DJF insolation (especially at low latitudes) and slightly lower SON insolation (Fig. 1).

The simulated hemispheric mean surface air temperature follows the insolation pattern. In the Northern Hemisphere there is a strong seasonal cycle in the early LIG experiments (130 ka_Gpi and $125 \mathrm{ka} \_\mathrm{Gpi}$ ) and reduced seasonal contrasts in the late LIG (120 ka_Gpi and 115 ka_Gpi) (Fig. 2 and Fig. 3a). The Southern Hemisphere temperatures show the opposite trend (Fig. 2 and Fig. 3b).

The two early LIG simulations with reduced GHG forcing (130 ka and $125 \mathrm{ka}$ ) give the same seasonal contrast in hemispheric mean surface air temperatures (not shown), albeit with slightly smaller absolute values.
The relatively warm JJA and cold DJF during the early LIG (130 ka to $125 \mathrm{ka}$ ) is also found by Lunt et al. (2013). They show that this is a robust signal computed by many different climate models. In contrast to our model results, Lunt et al. (2013) find a DJF warming in the Arctic computed by more than $70 \%$ of their model simulations, although the border of this warming is not well defined (see their Fig. 6b). This warming might be the result of the fact that their multimodel mean also includes simulations representing $127 \mathrm{ka}$ and $128 \mathrm{ka}$, during which GHGs were temporarily higher than their pre-industrial values. Due to sea ice melting feedbacks, this warming is enhanced in the Arctic. We compute a similar JJA warming as the other model simulations of Lunt et al. (2013), except that we find a strong warming at the coast of Antarctica, due to reduced sea ice. Both the multimodel mean of Lunt et al. (2013) and our NorESM simulations show a smaller annual compared to seasonal mean temperature difference. This is similar to insolation, where the largest changes to pre-industrial are also found in the seasonal data.

Figure 4 illustrates the difference between orbital and GHG forcing for the two $130 \mathrm{ka}$ simulations (130 ka and 130 ka_Gpi), which have the largest difference in GHG forcing (e.g. $23 \mathrm{ppm}$ for $\mathrm{CO}_{2}$; Table 1). The reduced GHG forcing results in a temperature reduction of up to $\sim 2{ }^{\circ} \mathrm{C}$, similar in all seasons with the largest change over the continents and at the high latitudes (Fig. 4 right column). In contrast, the $130 \mathrm{ka}$ insolation changes cause seasonal and hemispheric differences in surface air temperature on the order of $4-8^{\circ} \mathrm{C}$. The relatively large annual mean warming $\left(>2{ }^{\circ} \mathrm{C}\right)$ found at high latitudes (mainly southern high latitudes), compared to the relatively small change in annual mean insolation (Fig. 1), is mainly due to strong summer sea ice melting, causing a positive feedback stronger that the feedback related to winter sea ice growth.

Yin and Berger (2012) compare the effect of GHG versus insolation forcing for the last nine interglacials. They find different results for every interglacial, but also conclude that in general GHGs control the global annual mean temperatures, and that insolation plays a dominant role over the northern high latitudes. In contrast to our results, they find that southern high latitudes are mostly controlled by GHG forcing, while we find also an insolation effect. However it is difficult to compare our results directly as they take the insolation and GHG values from $127 \mathrm{ka}$, where GHGs were 


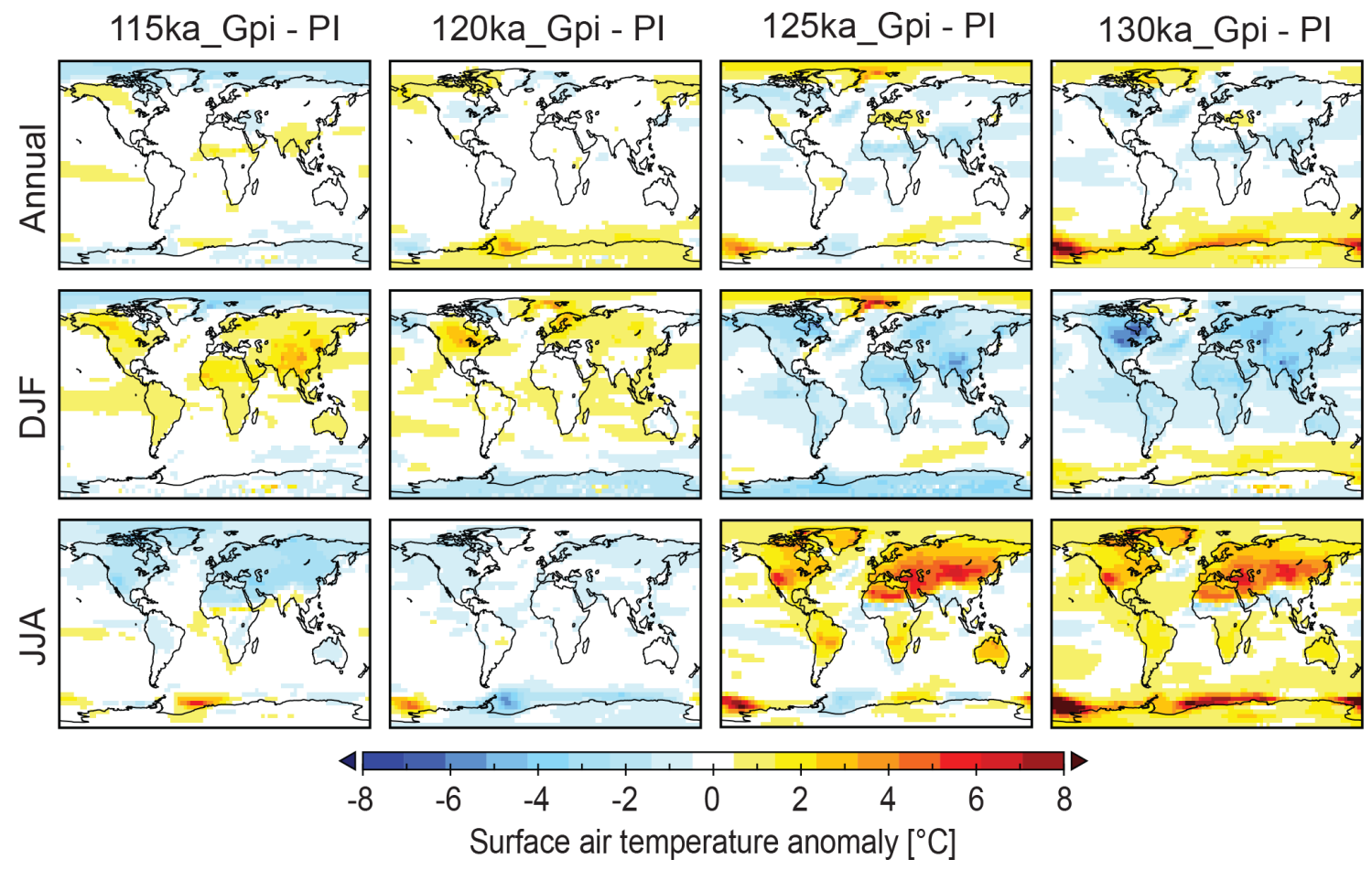

Figure 2. Surface air temperature difference between LIG time slices and PI. Only results from simulations with PI GHG forcing are shown. From right to left: $130 \mathrm{ka}$ _Gpi, $125 \mathrm{ka}$ _Gpi, $120 \mathrm{ka}$ _Gpi and $115 \mathrm{ka}$ _Gpi. Upper row shows annual, middle row shows DJF and bottom row shows JJA mean temperatures.
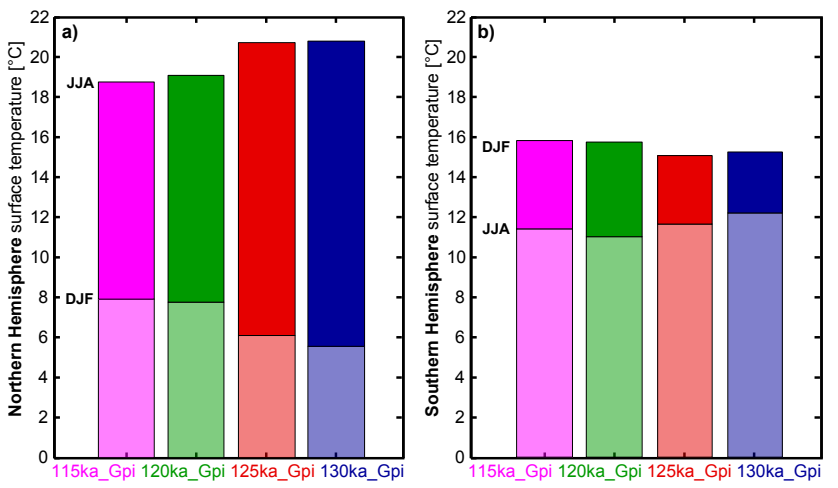

Figure 3. LIG hemispheric mean surface temperatures. (a) Northern Hemisphere and (b) Southern Hemisphere.

temporarily higher than at PI, in contrast to our reduced GHG values at $130 \mathrm{ka}$ and $125 \mathrm{ka}$.

\subsection{North Atlantic sea-surface temperatures}

The evolution of summer SSTs reconstructed in the four North Atlantic sediment cores through the LIG (Table 2) is shown together with simulated temperatures in Fig. 5. The temperature data from ODP 980 and CH69-K09 have a higher resolution and are therefore three-point smoothed (as is also done in Govin et al., 2012). The three northernmost cores (MD95-2010, ODP 980 and EW9302-JPC02) all show an increase in SSTs early in the LIG, with maximum temperatures around $125 \mathrm{ka}$, and a decrease towards $115 \mathrm{ka}$. In contrast, the southernmost core in the North Atlantic (CH69K09) records a steady increase from $130 \mathrm{ka}$, reaching a maximum at $\sim 119 \mathrm{ka}$, with only a very minor decrease thereafter.

We compare the sediment core data to our LIG simulations by extracting mean monthly SSTs (representing the upper $\sim 10 \mathrm{~m}$ of the water column) from the ocean grid boxes surrounding the sediment core locations. The red and light blue lines in Fig. 5 represent the LIG evolution based on the four simulations using pre-industrial GHGs. Temperature of three summer months (July, August and September) and three winter months (January, February, March) are shown. August and September are the months that fit the reconstructed SST pattern best, depending on the location. For the northern most sites (MD95-2010 and ODP 980) the maximum SST is reached at $125 \mathrm{ka}$. August is the only modelled month that has its maximum at $125 \mathrm{ka}$. Therefore, combined with a similar decrease after the peak warmth, this month fits the reconstructed SST patterns best. For EW9302-JPC2 the temperature peak is also reached at $125 \mathrm{ka}$ (which fits again modelled August SSTs). However it also shows a rapid SST increase before this optimum, and this fits the modelled September better. In the southernmost core (CH69-K09) an increase in SST is registered, with a flattening and possible decrease between 118 and $114 \mathrm{ka}$. The modelled month that captures this 

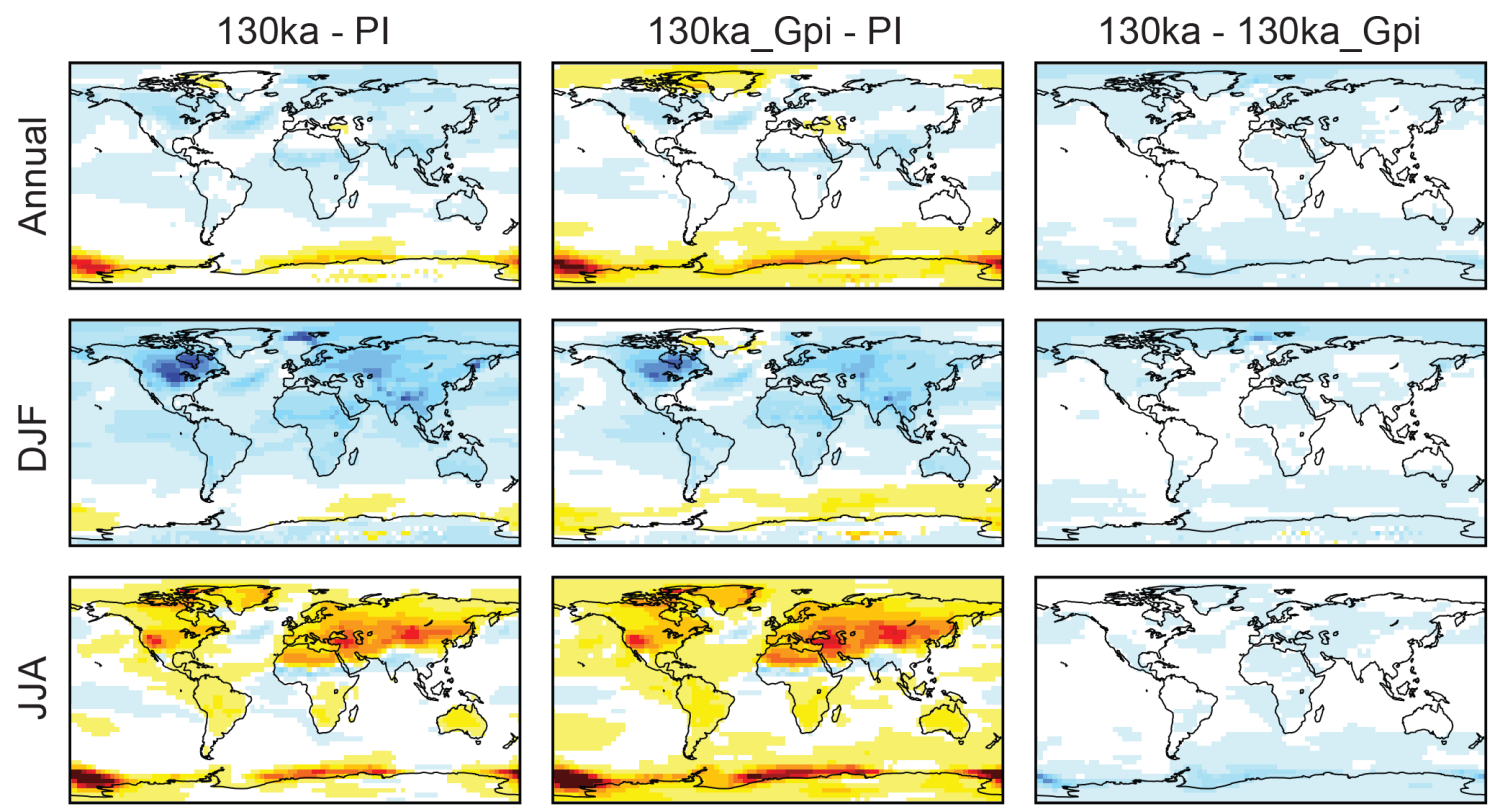

Effect of insolation \& GHG
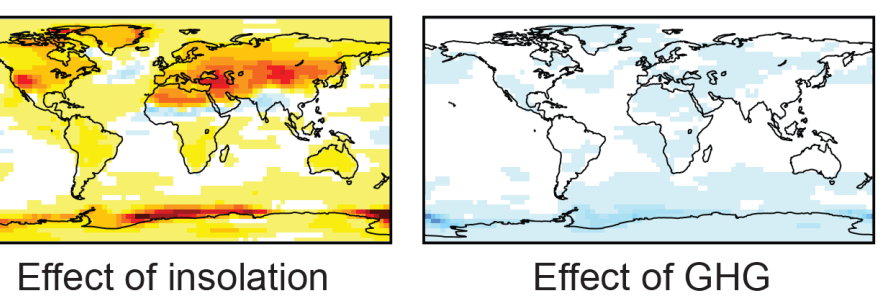

Effect of GHG

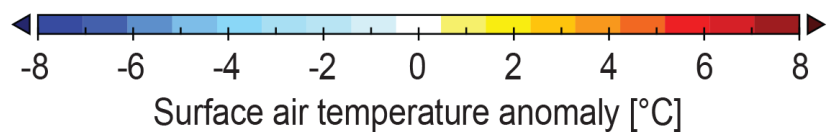

Figure 4. Effect of GHG versus insolation forcing on the surface air temperature difference between $130 \mathrm{ka}$ and PI. Left column shows run $130 \mathrm{ka}$ (insolation and GHG forcing for $130 \mathrm{ka}$ ), middle column indicates run $130 \mathrm{ka}$ _Gpi (130 ka insolation and PI GHG gas forcing), right column shows the difference between the first two columns. Upper row shows annual, middle row shows DJF and bottom row shows JJA mean temperatures.

increase best is September. However, it should be noted that the proxy records represent average summer values. Therefore, in order to compare our modelled results to the proxy derived SSTs we use shading to indicate the general summer and winter trends as computed by the model based on Aug-Sep and Feb-Mar, respectively. Also a $1{ }^{\circ} \mathrm{C}$ error in the data has been included in the shading. The comparison in Fig. 5 confirms that the proxy-based North Atlantic SST reconstructions follow summer insolation and are indeed indicative of summer temperatures. In contrast the simulated North Atlantic winter temperatures follow a different trend and reach their peak warmth only late during the LIG (after $\sim 120 \mathrm{ka}$, see also discussion in the next section).

The results presented here are computed from time-slice simulations, not from a transient simulation; therefore, we focus on the long-term trends ( $>5 \mathrm{ka}$ ). We expect a smooth transition from one time-slice experiment to the next if we only consider orbital changes. GHG concentrations, however, fluctuated during the LIG, and can possibly partly explain the variations found in the reconstructed SSTs. The high SST peak at around $128 \mathrm{ka}$ found in the four sediment cores can be related to the reconstructed higher GHGs at that time. In order to properly explain these short-term variations, and the rapid warming into the LIG, a transient simulation would be necessary.

Even though the simulated trend in general is comparable to the reconstructed SST evolution, a large offset of several degrees is found at $130 \mathrm{ka}$. For this period the match is largely improved when including reduced GHG concentrations (experiments $130 \mathrm{ka}$ and $125 \mathrm{ka}$; green lines/shading in Fig. 5, see also below). In order to explain the reconstructed low temperatures of the early LIG ( $\sim 130 \mathrm{ka})$, Govin et al. (2012) suggest that (in addition to the altered orbital configuration) there was inflow of meltwater to the North Atlantic from remnants of glacial ice sheets. They find a $\sim 1^{\circ} \mathrm{C}$ annual mean cooling at the locations of the three southern core sites in a model simulation perturbed with a large northern meltwater input (their Fig. 10a). For the summer season the temperature response is the same order of magnitude. Our simulations indicate lower surface ocean temperatures solely by reducing the levels of atmospheric GHG, without including freshwater from melting ice sheets. Both effects (reduced GHG values and freshwater input) cause about the same amount of cooling for the three southern sites. However, for the northernmost core site (MD95-2010), Govin et al. (2012) find a warming due to freshwater input. In contrast, we expect cooling at all core locations at around $130 \mathrm{ka}$ due to reduced 

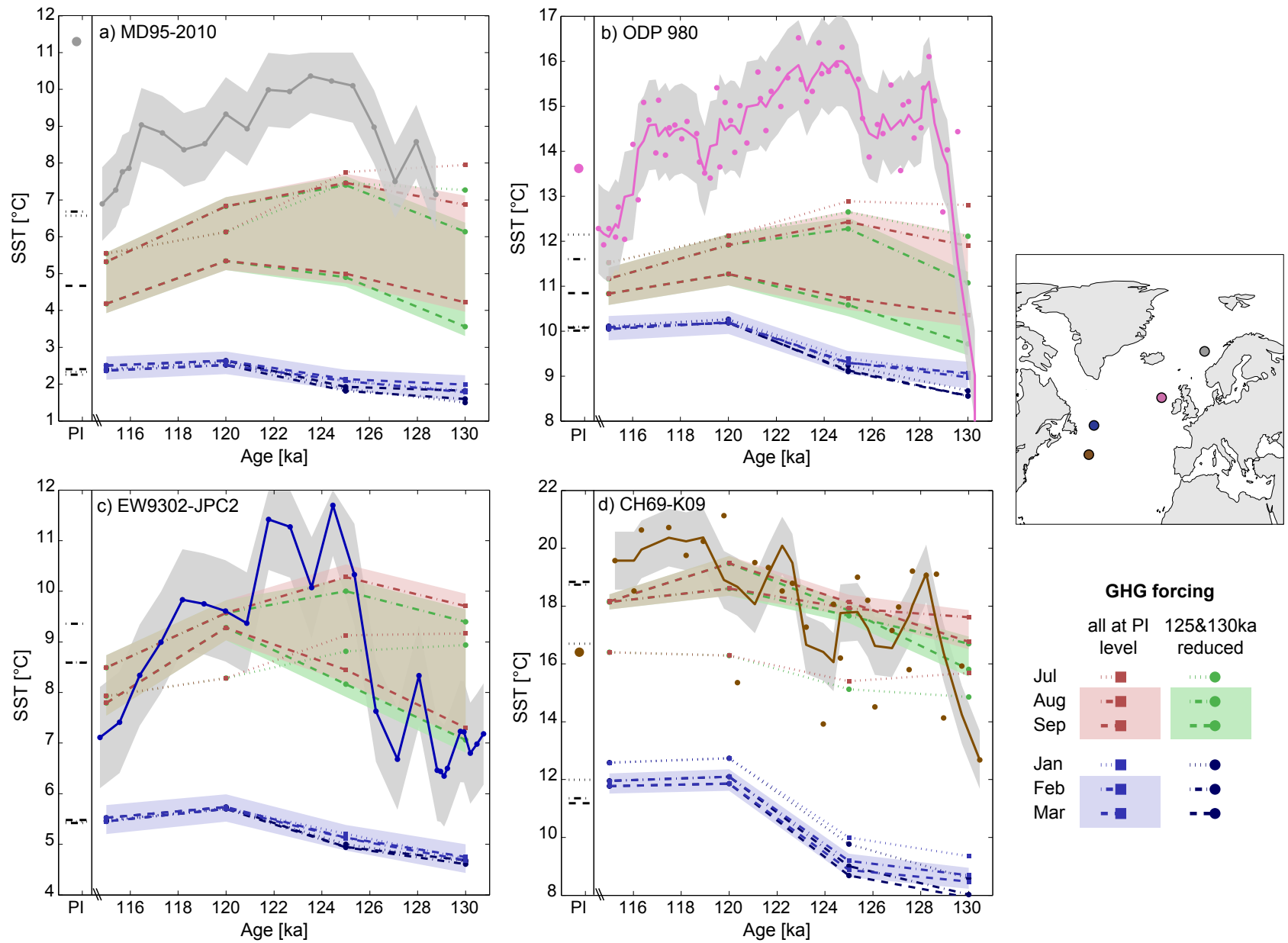

Figure 5. Reconstructed (solid lines) and modelled (dashed and dotted lines) SSTs for the four core locations: (a) Norwegian Sea core MD95-2010; (b) North Atlantic core ODP 980; (c) Labrador Sea core EW9302-JPC2; and (d) North Atlantic core CH69-K09. The red-brown and blue lines indicate the modelled LIG SST evolution with GHG forcing kept constant at PI levels for Jul-Aug-Sep and Jan-Feb-Mar, respectively. The green and dark blue lines show the simulated temperatures due to reduced GHG forcing at $125 \mathrm{ka}$ and $130 \mathrm{ka}$. The coloured shading indicates the best fitting summer (Aug and Sep; red for constant GHG forcing and green for reduced GHG forcing) and winter (Feb and Mar; blue, only shown for constant GHG forcing) months. The grey shading around the proxy data indicates possible errors and is set to $1{ }^{\circ} \mathrm{C}$. The total age uncertainty is less than $2500 \mathrm{yr}$ (see also Sect. 2.3). The horizontal bars on the left side of the figures indicate modelled monthly mean PI values. The dots on the left side of the figures represent late Holocene reconstructed SSTs (not available for EW9302-JPC2 and the value for MD95-2010 is taken from the nearby-located site MD95-2011). Note that, for the simulated SSTs, monthly means are computed using a fixed-day calendar (see discussion in Sect. 3.4).

GHGs. Govin et al. (2012) report that high northern latitude warming is a common feature simulated in freshwater experiments. However, in independent freshwater simulations by Holden et al. (2010), a high northern latitude cooling of up to $\sim 1{ }^{\circ} \mathrm{C}$ is found. Unfortunately, the proxy record at this location (MD95-2010) does not extend this far back in time, so we cannot use these data to confirm or discard either scenario. However for the other three core sites, it is likely that a combination of reduced GHGs and freshwater forcing is important for explaining the sea surface cooling.

In addition to lower GHG concentrations and freshwater forcing, the deglaciation of the Laurentide ice sheet (LIS) during the early LIG might have affected the North Atlantic
SSTs by changes in surface elevation and albedo over North America. For example, Renssen et al. (2009) show a North Atlantic SST cooling on the order of $1-3^{\circ} \mathrm{C}$ due to surface elevation and albedo changes associated with LIS melting during the early Holocene (at $\sim 9 \mathrm{ka}$ ). During that time the melting LIS caused a global sea-level rise of $\sim 5 \mathrm{~m}$ (Peltier, 2004). In contrast, a higher LIS-induced sea-level rise of $\sim 20 \mathrm{~m}$ is estimated between $130 \mathrm{ka}$ and $125 \mathrm{ka}$ (Kopp et al., 2009). In any case, the combined effect of surface elevation and albedo changes over North America is not well resolved. In a sensitivity study, Pausata et al. (2011) show that the changed albedo and topography of the LIS have opposite effects on Atlantic SSTs during the Last Glacial Maximum, 

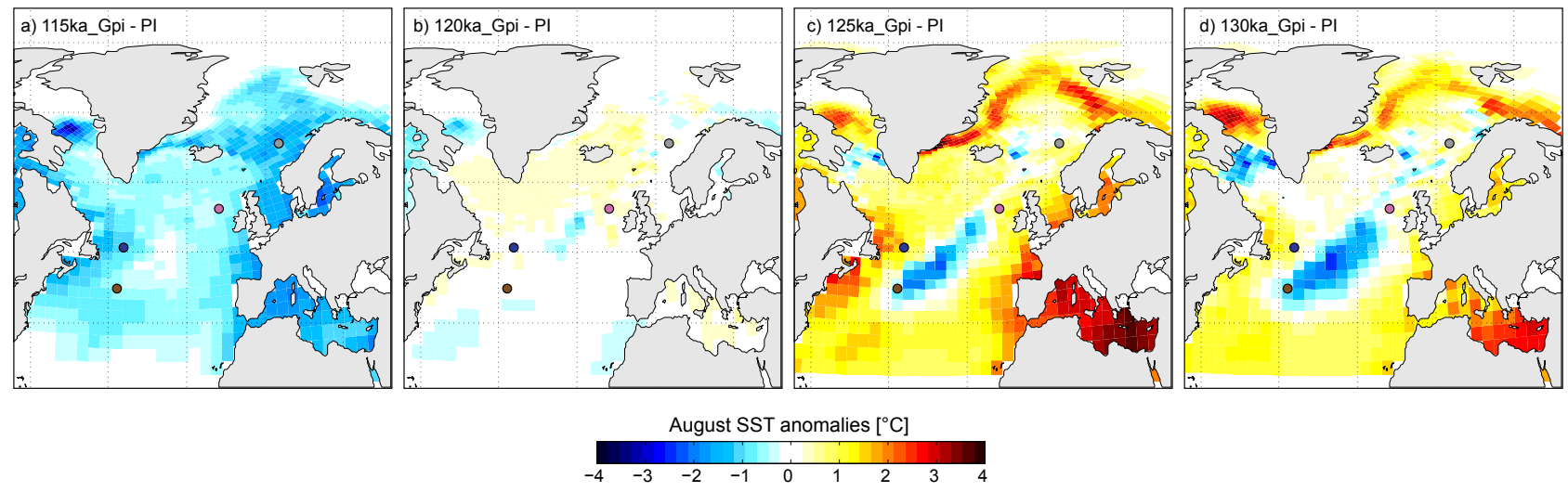

Figure 6. Modelled August SST anomaly compared to PI. Coloured dots indicate the core locations used in this study: (a) 115 ka_Gpi-PI; (b) 120 ka_Gpi-PI; (c) 125 ka_Gpi-PI; and (d) 130 ka_Gpi-PI. GHG forcing is fixed to PI values. Simulations with reduced GHG forcing are not shown but show a similar pattern.

and largely cancel each other. As the focus of this study is to isolate the effects of GHG and insolation forcing during the LIG and not on the deglaciation of large land-based ice masses, we did not include ice sheet meltwater, topography and albedo changes in our model simulations. Future research can resolve if including ice sheet changes can further improve the North Atlantic SSTs model-data fit during the early LIG.

Even though the general temperature evolution during the LIG is captured by the simulations, the model underestimates the temperatures at the two northernmost core locations over the entire LIG by $\sim 2-3{ }^{\circ} \mathrm{C}$ (MD95-2010 and ODP 980; Fig. 5a, b). A similar offset of $\sim 2{ }^{\circ} \mathrm{C}$ is found when comparing the reconstructed summer SST averaged over the last $3.5 \mathrm{kyr}$ (Govin et al., 2012) to the simulated PI SST for ODP 980 (Fig. 5b, left column). For MD952010 no adequate Holocene record is available. However, the nearby-located MD95-2011 does provide a high-resolution late Holocene record (Andersson et al., 2003). Both MD95 cores record very similar SSTs during the deglaciation, and therefore late Holocene values of MD95-2011 are likely representative for MD95-2010. Applying the Govin et al. (2012) relationship between summer SSTs and the percentage of the polar planktic species $N$. pachyderma sinistral to the counts of Andersson et al. (2003) gives an average late Holocene (last $3 \mathrm{kyr}$ ) SST of approximately $11.3^{\circ} \mathrm{C}$. This is about $5{ }^{\circ} \mathrm{C}$ higher than the modelled PI SSTs at that location, indicating that the model underestimates the simulated modern SSTs and that the simulated modern offset is larger than the $\sim 3{ }^{\circ} \mathrm{C}$ difference between simulated and proxy SSTs during the LIG (Fig. 5a). In contrast, again no real offset is found between reconstructed and simulated late Holocene/PI SSTs for the more southern located site CH69-K09 (Fig. 5d, Govin et al. (2012)). Unfortunately EW9302-JPC2 does not cover the Holocene (Rasmussen et al., 2003). The (possibly time independent) offset in the two northernmost core locations might be due to reduced inflow of relatively warm Atlantic water into the Nordic Seas, causing too cold modelled temperatures at the northernmost cores. This is a general feature of NorESM, and also the pre-industrial climate has a too weak Nordic Seas inflow (Zhang et al., 2012). On the other hand, the reconstructed SSTs can be too high, as the Norwegian Sea (core MD95-2010) SST estimates are derived from a defined linear relationship between the percentage of a polar foraminifera species ( $N$. pachyderma sinistral) and summer SSTs from the MARGO data set. The total error in this calibration is $1.8^{\circ} \mathrm{C}$ (Govin et al., 2012). The SSTs at the North Atlantic core ODP 980 are reconstructed using the modern analogue technique on foraminifera faunal assemblages. The estimated error for this temperature reconstruction is between 0.5 and $2{ }^{\circ} \mathrm{C}$ (Cortijo et al., 1999). In Fig. 5 a conservative estimated error of $1{ }^{\circ} \mathrm{C}$ for the reconstructed SSTs is indicated by the shading. Another probable source for the mismatch between modelled and reconstructed SSTs relates to the depth at which the foraminifera live and create their shell that captures the ocean conditions (e.g. Lohmann et al., 2013; Telford et al., 2013). This habitat depth differs from species to species, and could easily be below the upper $10 \mathrm{~m}$ of the water column, the value defining sea surface in NorESM. However, as the reconstructed temperatures are calibrated to ocean temperatures taken at $10 \mathrm{~m}$ water depth, errors occurring will be small compared to the standard calibration error (see above). Concluding, as only the two northernmost temperature records are underestimated by the model, the most likely cause is the models general underestimation of inflow of warm Atlantic water into the Nordic Seas.

The modelled SSTs are taken from the grid boxes directly surrounding the four sediment core locations. The area of these grid boxes is quite large and ranges between 10000 and $60000 \mathrm{~km}^{2}$, with the smaller areas closer to the ocean model's pole at Greenland. When repeating the analysis for 

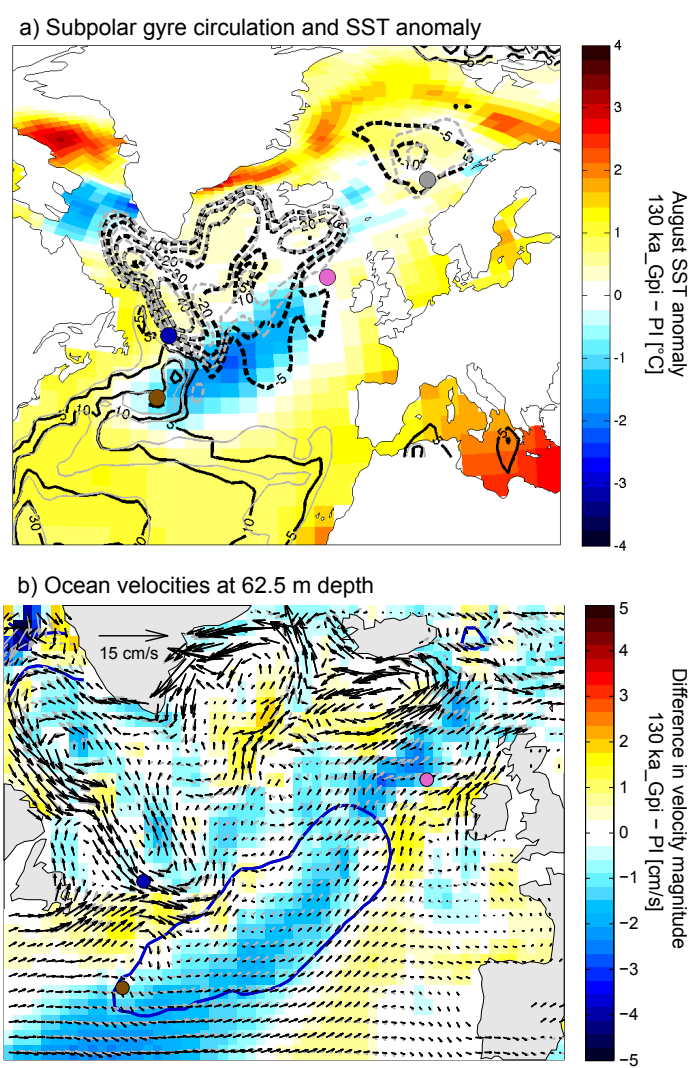

Figure 7. (a) Horizontal stream function [Sv] showing the subpolar gyre on top of the SST anomaly between $130 \mathrm{ka}$ _Gpi and PI of Fig. $6 \mathrm{~d}\left[{ }^{\circ} \mathrm{C}\right]$. Bold black contour lines indicate $130 \mathrm{ka}$ _Gpi and thin grey lines PI stream functions. SST colour scale is the same as in Fig. 6. (b) Subsurface ocean velocities at $62.5 \mathrm{~m}$ depth. Black and grey arrows indicate the strength and direction of the velocities for 130 ka_Gpi and PI, respectively. Background colour shows the difference in the velocity strength between $130 \mathrm{ka}$ _Gpi and PI. Dark blue contour indicates the location of the SST anomaly of (a), showing the contour of $-0.8{ }^{\circ} \mathrm{C}$. Core site locations are shown as coloured dots.

SSTs taken from the grid boxes surrounding the original grid box, we find similar trends over the LIG, with maxima occurring at the same time. Also the simulations with reduced GHG forcing are always colder at $130 \mathrm{ka}$ compared to the 130 ka simulation with PI GHG forcing. However, the absolute SSTs are different for the neighbouring grid boxes by up to $1-2{ }^{\circ} \mathrm{C}$ (see also Fig. 6 and discussion on spatial variations below). The mean over the nine grid boxes is very similar (less than $0.5^{\circ} \mathrm{C}$ difference) to the values of the central, original grid box.

Apart from not capturing the small timescale variations and the general offset in the two northernmost temperature records, our modelled North Atlantic temperature evolution reproduces the reconstructed trends quite well. This contrasts the overall poor model-data fit found by Lunt et al. (2013). We find a relatively good fit, because we focus on
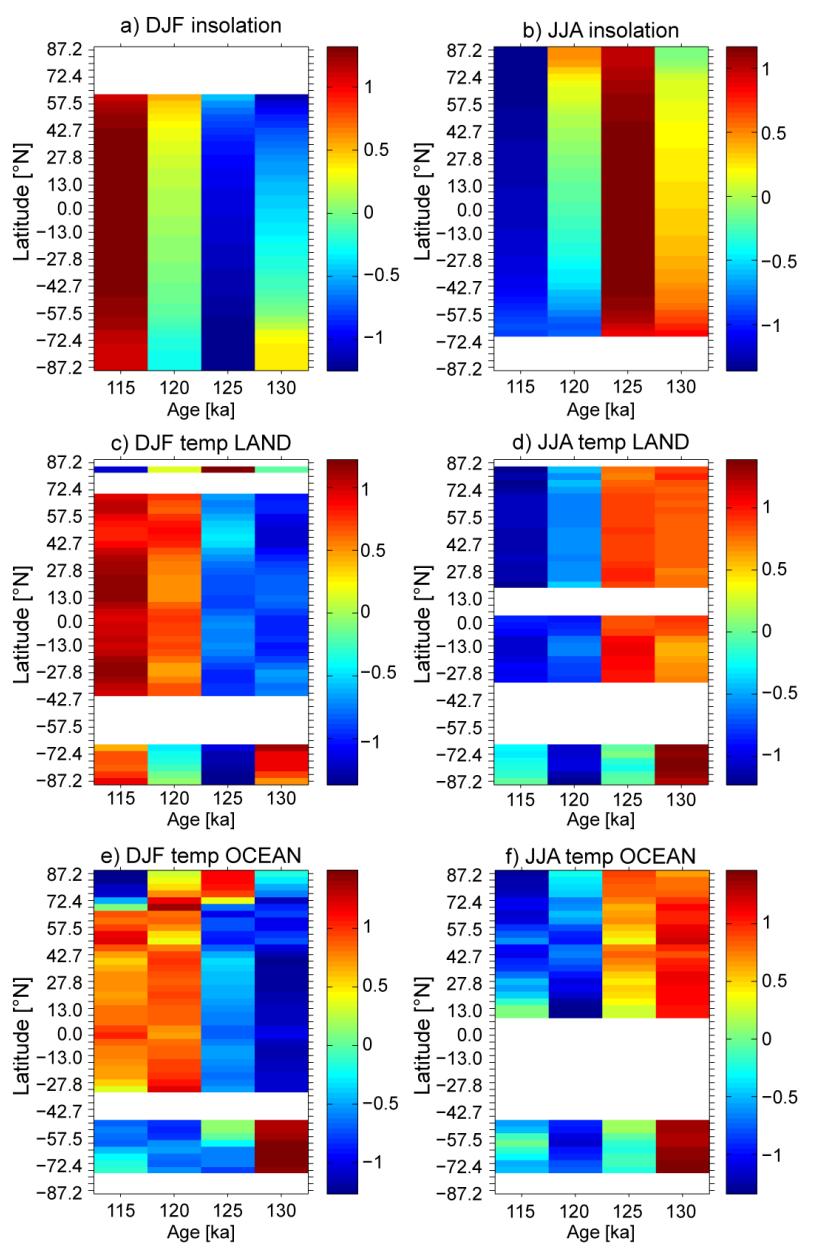

Figure 8. Zonal mean LIG insolation and surface air temperature normalized per latitude. (a) DJF insolation; (b) JJA insolation; (c) DJF temperature over land; (d) JJA temperature over land; (e) DJF temperature over ocean; (f) JJA temperature over ocean. Excluded are results for latitudes where the insolation varies less than $5 \mathrm{~W} \mathrm{~m}^{-2}$ (Fig. 8a, b) and where the temperature varies less than half of the mean variations $\left(0.7^{\circ} \mathrm{C}\right.$ for Fig. $8 \mathrm{c}$, d and $0.3{ }^{\circ} \mathrm{C}$ for Fig. 8e, f). Note that, due to the normalization procedure, different latitudes cannot directly be compared to one another. For spatial changes within each time slice, we refer to Fig. 2.

a specific region (North Atlantic) and investigate the temporal evolution of this region. The records we compare our modelled temperatures with are all transferred to one common timescale, which is essential when looking at such relatively short time periods close to the resolution uncertainty of the reconstructed record. Unfortunately all other reconstructed LIG temperature records are not placed on one common timescale and/or lack the high resolution. Therefore, this exercise cannot be repeated on a global scale, yet. A global data-model comparison is therefore only possible when averaging over the entire LIG or over the warmest part of the LIG. However, by doing so, Lunt et al. (2013) find a poor fit. Especially over the high northern latitudes, the modelled 
temperatures underestimate the early LIG warming, as compared to the proxy data. This could be due to model deficits (e.g. too small inflow of warm Atlantic water into the Nordic Seas in NorESM), but also due to the mixture of many different types of proxy data that comprise the data set (Turney and Jones, 2010), recording different parts of the year (annual, seasonal or monthly means) and different parts of the LIG. The fact that modelled JJA or warmest-month mean temperatures fit the proxy data better (Lunt et al., 2013) emphasizes the seasonally biased character of the LIG temperature data set.

The reconstructed maximum summer SST at $\sim 125 \mathrm{ka}$, as depicted by the three northernmost sediment cores, is indicative of a large-scale pattern also simulated by the model for the entire North Atlantic (Fig. 6). The warmth is most pronounced at the continental margins, and is not captured by the open ocean sediment core locations. In contrast to the general pattern of warming, the SSTs in the centre of the North Atlantic are colder during the LIG than at PI, a feature most pronounced during the early LIG (125 ka and $130 \mathrm{ka})$. This negative SST anomaly corresponds to a small expansion of the southeastern part of the subpolar gyre early in the LIG, shifting the front between relatively cold subpolar water and warm subtropical water further southeast (Fig. 7a). During the late LIG (120 ka and $115 \mathrm{ka})$, the subpolar gyre is not expanded and corresponds to its PI location. In contrast to its size, the maximum strength of the LIG subpolar gyre is similar in all LIG and PI simulations. The gyre expansion is most likely connected to a changed in the wind stress curl which is strengthened in this part of the Atlantic and shows a slightly more zonal pattern in the early LIG simulations compared to the PI (not shown). At the same time we find a shift in the main pathway of the North Atlantic Current, where the early LIG simulation (130 ka_Gpi) shows a weakened and eastward deflected current in the central part of the North Atlantic close to the Rockall Plateau combined with a stronger current closer to the European coast, compared to PI (Fig. 7b). The eastward shift of the North Atlantic Current is combined with a slightly higher long-term mean maximum Atlantic meridional overturning circulation (AMOC) strength of $27 \mathrm{~Sv}$ during the $130 \mathrm{ka}$ _Gpi simulation versus the $21 \mathrm{~Sv}$ of the PI simulation. Further research investigating the cause of the shift in the North Atlantic Current in this area and the possible interplay between changes to the subpolar gyre circulation, AMOC and hydrography is required, but it is beyond the scope of this study. For a discussion on present-day shifts of the North Atlantic Current, we refer to Hakkinen and Rhines (2009).

\subsection{Timing of maximum last interglacial warmth}

Recent studies discuss the timing of the maximum warmth during the LIG (e.g. Govin et al., 2012; Bakker et al., 2013). SST data from the Southern Ocean indicate an early maximum, possibly preceding the temperature increase in the Northern Hemisphere (Govin et al., 2012). In contrast, transient model simulations covering this time period show Southern Hemisphere January peak warmth only after $\sim 120 \mathrm{ka}$ (Bakker et al., 2013).

Figure 8 shows the timing of maximum insolation (Fig. 8a and b) and peak warmth (Fig. 8c-f) for our LIG simulations (reduced GHG simulations not shown). We show longitudinal mean values, as the variations in this direction are small compared to the latitudinal and seasonal differences. The seasonal (DJF and JJA) values are normalized per latitude so that the peak insolation and warmth per latitude can easily be recognized. For further clarity we exclude results for latitudes where the insolation varies less than $5 \mathrm{~W} \mathrm{~m}^{-2}$ (Fig. 8a, b) and where the temperature varies less than half of the mean variations $\left(0.7^{\circ} \mathrm{C}\right.$ for Fig. $8 \mathrm{c}, \mathrm{d}$ and $0.3{ }^{\circ} \mathrm{C}$ for Fig. $\left.8 \mathrm{e}, \mathrm{f}\right)$.

Summer (JJA) insolation is at its maximum at $125 \mathrm{ka}$ for most latitudes. Only at high southern latitudes, $125 \mathrm{ka}$ and 130 ka show a combined maximum. In contrast, winter (DJF) insolation has a late LIG (115 ka) maximum at all latitudes.

Simulated Northern Hemisphere temperatures largely follow local insolation, with early peak warmth in summer (JJA, 130-125 ka) and a late peak warmth in winter (DJF, $\sim 120-115 \mathrm{ka}$ ), except for high northern latitudes, where winter temperatures peak at $\sim 125 \mathrm{ka}$. In the mid- to high latitudes of the Southern Hemisphere, temperatures largely follow the insolation pattern. Between $\sim 45^{\circ} \mathrm{S}$ and $90^{\circ} \mathrm{S}$ in both austral winter and summer, above land and ocean, the temperature peaks at around $130 \mathrm{ka}$. Above Antarctica $115 \mathrm{ka}$ also shows high austral summer (DJF) temperatures, and therefore the Antarctic summer peak warmth could either occur late $(\sim 115 \mathrm{ka})$ or early $(\sim 130 \mathrm{ka})$ in the LIG. This is in contrast with the clear early $(\sim 130 \mathrm{ka})$ summer peak warmth in the Southern Ocean, and hence explains both the early Southern Ocean peak as found by Govin et al. (2012) and the late Antarctica peak described by multi-model mean of Bakker et al. (2013).

An important difference between our study and that of Bakker et al. (2013) is that we performed equilibrium runs with a coupled GCM, whereas Bakker et al. (2013) describe transient simulations with simplified climate models (EMICs) and accelerated GCMs. Most of the Bakker et al. (2013) transient simulations are forced with temporalvarying GHG concentrations, providing a higher resolution LIG temperature evolution. Unfortunately, in most of the model simulations they cannot pinpoint the timing of peak warmth in Southern Ocean as the computed temperature variations over the LIG are too small. The two models that do simulate significant peak temperatures over most of the Southern Hemisphere (FAMOUS and LOVECLIM) show an early LIG January temperature maximum over the Southern Ocean combined with a late LIG maxima over Antarctica, similar to our results. Bakker et al. (2013) suggest that the January peak warmth simulated by FAMOUS and LOVECLIM in the Southern Ocean at around $127 \mathrm{ka}$ and $120 \mathrm{ka}$, 
respectively, is related to changes in the AMOC, although the mechanism needs to be further investigated.

We propose that the fact that the Southern Ocean peaks early also in austral summer (DJF), while direct insolation is still relatively low (Fig. 1 and Fig. 8a), shows the integrating effect of the ocean: at high latitudes of the Southern Hemisphere (above $\sim 40^{\circ} \mathrm{S}$ ), which is dominated by ocean, the relatively high SON insolation is efficiently stored and results in warm surface temperatures also in the other seasons. The warm Southern Ocean induces sea ice retreat and thinning, causing increasing heat fluxes between the ocean and the atmosphere. Larger heat fluxes, together with local intermediate insolation, result in relatively high early $(\sim 130 \mathrm{ka})$ Antarctic temperatures (Fig. 8c).

Similarly, even though DJF insolation over the Southern Ocean peaks at $\sim 115 \mathrm{ka}$, the simulated ocean temperatures are relatively low during that period. This shows again the integrating effect of the ocean, where the slightly higher DJF insolation is compensated by the relatively low SON insolation. In contrast, on land, Antarctic DJF temperatures are more directly influenced by DJF insolation, and show a maximum at $115 \mathrm{ka}$.

Reducing the GHG concentrations in the early LIG (125 and $130 \mathrm{ka}$ ) results in a similar timing of peak warmth (not shown), except over Antarctica. There, the lower GHGs reduce the early LIG temperatures. As a consequence the peak warmth shifts to $115 \mathrm{ka}$, supporting the results of Bakker et al. (2013) but contrasting reconstructed early Antarctic peak warmth. Please note again that this is based on simulations every $5 \mathrm{ka}$, and that the transient high GHG concentrations at $\sim 128 \mathrm{ka}$ are not captured in this study. It is possible that these high GHGs resulted in short-term $(<3 \mathrm{ka})$ relatively high temperatures over Antarctica, possibly indicating an early Antarctic peak warmth. However, Bakker et al. (2013) do not find this in their models forced by transient GHG concentrations.

For the computation of peak warmth, we focussed on the JJA and DJF seasons. However, as can be seen from Fig. 5 the different months within a season have distinct evolutions. The peak warmth as discussed here indicates the latitudinal mean seasonal timing. One should be careful with extrapolating our results to a particular month (see also below) and specific location.

\subsection{Discussion of calendar definition}

The extrapolation to monthly values is hampered due to the use of a fixed-day calendar with spring equinox fixed to 21 March: we define each month to have the same number of days as its modern equivalent. However, this changes with variations in precession, and could cause a bias when looking at a particular month. The effect of not using a fixed-angular calendar is largest for the late autumn (SON) months (see also Chen et al., 2011). For spring (MAM) the difference is close to zero.
In Fig. 5 we compare simulated monthly-mean ocean temperatures to reconstructed SSTs. Because of the fixed-day calendar, we include some days from the preceding or following month in our monthly mean values. Using a correct fixed-angular calendar evolution of the LIG summer months would therefore be slightly different than the curves shown in Fig. 5. However, as we use several summer months in the comparison, and the main conclusion is that the proxy records show a summer signal (in the broad sense), the use of a fixed-day calendar in the model will not significantly bias the main conclusions based on this figure.

The same is true for Fig. 6, which shows maps of August temperatures; the shift in the calendar will not greatly alter the simulated SST patterns of relatively warm SSTs during the early LIG and cold SSTs during the late LIG. Unfortunately we did not save the daily model output due to the exceedingly large amount of data storage required, so we cannot recalculate the monthly mean values presented here. However, as a simple test of the impact on the JJA and DJF results, we shifted the definition of the months through time by including $20 \%$ of the month before or after in calculating the JJA and DJF means given in Fig. 8, and the main pattern of early JJA warming and late DJF warming is still valid. Therefore we do not think that the definition of the calendar will change our main results.

Other modelling studies focussing on the LIG (e.g. Bakker et al., 2013; Lunt et al., 2013) also use a fixed-day calendar, so our results can be directly compared to these studies. We suggest, however, that in future palaeo-simulations monthly mean values should be corrected to a fixed-angular calendar.

\section{Conclusions}

We performed six time-slice simulations with the lowresolution version of the Norwegian Earth System Model (NorESM1-L) covering the LIG from 130 to $115 \mathrm{ka}$. In four simulations only the orbital forcing was changed representing 130, 125, 120 and $115 \mathrm{ka}$. The two early LIG (130 and $125 \mathrm{ka}$ ) simulations were repeated with reduced GHG forcing.

Our simulations show small changes in annual mean atmospheric temperatures, but a significant change in seasonal temperatures over the LIG. In the Northern Hemisphere the seasonal cycle is enhanced early in the LIG $(\sim 130-125 \mathrm{ka})$, and reduced in the later part $(\sim 115 \mathrm{ka})$. The Southern Hemisphere temperatures indicate the opposite, with a smaller seasonal contrast early in the LIG and a similar or slightly larger seasonal cycle later. We show that the seasonal and hemispheric differences are the result of changes in insolation forcing. In contrast, a reduction in GHG forcing causes a global and seasonal-independent cooling.

The NorESM1-L simulations capture the general trend of LIG summer (August/September) SSTs, as shown by four sediment cores in the North Atlantic, confirming that the 
proxy temperatures represent summer. Reduced GHG levels during the early part of the LIG period (especially at $\sim 130 \mathrm{ka}$ ), as indicated by ice core data (e.g. Petit et al., 1999), improve the model-data fit by lowering the simulated temperatures. The cooling can be further emphasized by the retreat of the Laurentide ice sheet, due to freshwater forcing (Govin et al., 2012), or possibly by elevation or albedo changes (see Pausata et al. (2011) and Renssen et al. (2009) for this feedback during the Last Glacial Maximum and Holocene, respectively).

In general, the timing of peak warmth follows the local insolation maximum causing an early ( $\sim 130-125 \mathrm{ka})$ summer (JJA) and late $(\sim 115 \mathrm{ka})$ winter (DJF) peak warmth, with two main exceptions. First, the Southern Ocean austral summer peak warmth occurs already in the early LIG $(\sim 130 \mathrm{ka})$, even though local insolation is only slightly increased. This is probably due to the integrating effect of the ocean, storing autumn (SON) heat resulting in relatively warm temperatures, year-round. Second, Antarctica has two maxima in austral summer (DJF) temperatures, around 130 and $115 \mathrm{ka}$. Here the early peak $(\sim 130 \mathrm{ka})$ could be the result of the adjacent warm Southern Ocean combined with intermediate insolation. Reduced GHG concentrations at the early LIG lower the Antarctic temperatures and cause a single late LIG peak warmth at $\sim 115 \mathrm{ka}$.

Acknowledgements. We thank Aline Govin and Bjørg Risebrobakken for providing the sediment core temperatures and discussing an early comparison of these data to our model results. We also thank the two anonymous reviewers and the editor for their constructive comments. This project was funded by Past4Future "Climate change - Learning from the past climate", a Collaborative Project under the 7th Framework Programme of the European Commission (grant agreement no. 243908) and was supported by the DYNAWARM project of the Centre for Climate Dynamics at the Bjerknes Centre for Climate Research.

Edited by: U. Mikolajewicz

\section{References}

Andersson, C.,Risebrobakken, B., Jansen, E., and Dahl, S. O.: Late Holocene surface ocean conditions of the Norwegian Sea (Vøring Plateau), Paleoceanography, 18, 1044, doi:10.1029/2001PA000654, 2003.

Assmann, K. M., Bentsen, M., Segschneider, J., and Heinze, C.: An isopycnic ocean carbon cycle model, Geosci. Model Dev., 3, 143-167, doi:10.5194/gmd-3-143-2010, 2010.

Bakker, P., Stone, E. J., Charbit, S., Gröger, M., Krebs-Kanzow, U., Ritz, S. P., Varma, V., Khon, V., Lunt, D. J., Mikolajewicz, U., Prange, M., Renssen, H., Schneider, B., and Schulz, M.: Last interglacial temperature evolution - a model inter-comparison, Clim. Past, 9, 605-619, doi:10.5194/cp-9-605-2013, 2013.

Bentsen, M., Bethke, I., Debernard, J. B., Iversen, T., Kirkevåg, A., Seland, Ø., Drange, H., Roelandt, C., Seierstad, I. A., Hoose, C., and Kristjánsson, J. E.: The Norwegian Earth System Model, NorESM1-M - Part 1: Description and basic evaluation of the physical climate, Geosci. Model Dev., 6, 687-720, doi:10.5194/gmd-6-687-2013, 2013.

Berger, A. L.: Long term variations of caloric insolation resulting from the Earth's orbital elements, Quaternary Res., 9, 139-167, 1978.

Born, A., Nisancioglu, K. H., and Risebrobakken, B.: Late Eemian warming in the Nordic Seas as seen in proxy data and climate models, Paleoceanography, 26, PA2207, doi:10.1029/2010PA002027, 2011.

CAPE Last Interglacial Project Members: Last Interglacial Arctic warmth confirms polar amplification of climate change, Quaternary Sci. Rev., 25, 1383-1400, 2006.

Chen, G-S, Kutzbach, J. E., Gallimore, R., and Liu, Z.: Calendar effect on phase study in paleoclimate transient simulation with orbital forcing, Clim. Dyn., 37, 1949-1960, doi:10.1007/s00382010-0944-6, 2011.

Clark, P. U. and Huybers, P.: Interglacial and future sea level, Nature, 462, 856-857, 2009.

Cortijo, E., Lehman, S., Keigwin, L., Chapman, M., Paillard, D., and Labeyrie, L.: Changes in meridional temperature and salinity gradients in the North Atlantic Ocean $\left(30-72^{\circ} \mathrm{N}\right)$ during the last interglacial period, Paleoceanography, 14, 23-33, 1999.

Govin, A., Braconnot, P., Capron, E., Cortijo, E., Duplessy, J.C., Jansen, E., Labeyrie, L., Landais, A., Marti, O., Michel, E., Mosquet, E., Risebrobakken, B., Swingedouw, D., and Waelbroeck, C.: Persistent influence of ice sheet melting on high northern latitude climate during the early Last Interglacial, Clim. Past, 8, 483-507, doi:10.5194/cp-8-483-2012, 2012.

Holden, P. B., Edwards, N. R., Wolff, E. W., Lang, N. J., Singarayer, J. S., Valdes, P. J., and Stocker, T. F.: Interhemispheric coupling, the West Antarctic Ice Sheet and warm Antarctic interglacials, Clim. Past, 6, 431-443, doi:10.5194/cp-6-431-2010, 2010.

Hakkinen, S., and Rhines, P. B.: Shifting surface currents in the northern North Atlantic Ocean, J. Geophys. Res., 114, C04005, doi:10.1029/2008JC004883, 2009.

Iversen, T., Bentsen, M., Bethke, I., Debernard, J. B., Kirkevåg, A., Seland, Ø., Drange, H., Kristjansson, J. E., Medhaug, I., Sand, M., and Seierstad, I. A.: The Norwegian Earth System Model, NorESM1-M - Part 2: Climate response and scenario projections, Geosci. Model Dev., 6, 389-415, doi:10.5194/gmd6-389-2013, 2013.

Jansen, E., Overpeck, J. T., Briffa, K. R., Duplessy, J.-C., Joos, F., Masson-Delmotte, V., Olago, D., Otto-Bliesner, B., Peltier, W. R., Rahmstorf, S., Ramesh, R., Raynaud, D., Rind, D., Solomina, O., Villalba, R., and Zhang, D.: Palaeoclimate, in: Climate Change 2007: The Physical Science Basis, Contribution of Working Group I to the Fourth Assessment Report of the Intergovernmental Panel on Climate Change, edited by: Solomon, S., Qin, D., Manning, M., Chen, Z., Marquis, M., Averyt, K. B., Tignor, M., and Miller, H. L., Cambridge University Press, Cambridge, UK and New York, NY, USA, 2007.

Kaspar, F., Kühl, N., Cubasch, U., and Litt, T.: A model-data comparison of European temperatures in the Eemian interglacial, Geophys. Res. Lett., 32, L11703, doi:10.1029/2005GL022456, 2005. 
Kopp, R. E., Simons, F. J., Mitrovica, J. X., Maloof, A. C., and Oppenheimer, M.: Probabilistic assessment of sea level during the last interglacial stage, Nature, 462, 863-867, 2009.

Kukla, G. J., Bender, M. L., de Beaulieu, J.-L., Bond, G., Broecker, W. S., Cleveringa, P., Gavin, J. E., Herbert, T. D., Imbrie, J., Jouzel, J., Keigwin, L. D., Knudsen, K.-L., McManus, J. F., Merkt, J., Muhs, D. R., Müller, H., Poore, R. Z., Porter, S. C., Seret, G., Shackleton, N. J., Turner, C., Tzedakis, P. C., and Winograd, I. J.: Last interglacial climates, Quaternary Res., 58, 2-13, 2002.

Labeyrie, L., Leclaire, H., Waelbroeck, C., Cortijo, E., Duplessy, J. C., Vidal, L., Elliot, M., and Le Coat, B.: Temporal variability of the surface and deep waters of the North West Atlantic Ocean at orbital and millenial scales, Geophys. Monogr., 112, 77-98, 1999.

Leduc, G., Schneider, R., Kim, J.-H., and Lohmann, G.: Holocene and Eemian sea surface temperature trends as revealed by alkenone and $\mathrm{Mg} / \mathrm{Ca}$ paleothermometry, Quaternary Sci. Rev., 29, 989-1004, 2010.

Lenton, T. M., Held, H., Kriegler, E., Hall, J. W., Lucht, W., Rahmstorf, S., and Schellnhuber, H. J.: Tipping elements in the Earth's climate system, P. Natl. Acad. Sci. USA, 105, 1786-1793, 2008.

Levitus, S. and Boyer, T. P.: World Ocean Atlas Volume 4: Temperature, NOAA Atlas NESDIS 4, US Government Printing Office, Washington, DC, 117 pp., 1994.

Lohmann, G., Pfeiffer, M., Laepple, T., Leduc, G., and Kim, J. H.: A model-data comparison of the Holocene global sea surface temperature evolution, Clim. Past, 9, 1807-1839, doi:10.5194/cp-9-1807-2013, 2013.

Loulergue, L., Schilt, A., Spahni, R., Masson-Delmotte, V., Blunier, T., Lemieux, B., Barnola, J.-M., Raynaud, D., Stocker, T. F., and Chappellaz, J.: Orbital and millennial-scale features of atmospheric $\mathrm{CH}_{4}$ over the past 800,000 years, Nature, 453, 383-386, 2008.

Lüthi, D., Le Floch, M., Bereiter, B., Blunier, T., Barnola, J.-M., Siegenthaler, U., Raynaud, D., Jouzel, J., Fischer, H., Kawamura, K., and Stocker, T. F.: High-resolution carbon dioxide concentration record 650,000-800,000 years before present, Nature, 453, 379-382, 2008.

Lunt, D. J., Abe-Ouchi, A., Bakker, P., Berger, A., Braconnot, P., Charbit, S., Fischer, N., Herold, N., Jungclaus, J. H., Khon, V. C., Krebs-Kanzow, U., Langebroek, P. M., Lohmann, G., Nisancioglu, K. H., Otto-Bliesner, B. L., Park, W., Pfeiffer, M., Phipps, S. J., Prange, M., Rachmayani, R., Renssen, H., Rosenbloom, N., Schneider, B., Stone, E. J., Takahashi, K., Wei, W., Yin, Q., and Zhang, Z. S.: A multi-model assessment of last interglacial temperatures, Clim. Past, 9, 699-717, doi:10.5194/cp9-699-2013, 2013.

McManus, J. F., Oppo, D. W., and Cullen, J.: A 0.5-million-year record of millenial-scale climate variability in the North Atlantic, Science, 283, 971-975, 1999.

Meehl, G., Stocker, T. F., Collins, W. D., Friedlingstein, P., Gaye, A. T., Gregory, J. M., Kitoh, A., Knutti, R., Murphy, J. M., Noda, A., Raper, S. C. B., Watterson, I. G., Weaver, A. J., and Zhao, Z.-C.: Global climate projections, in: Climate Change 2007: The Physical Science Basis, Contribution of Working Group I to the Fourth Assessment Report of the Intergovernmental Panel on Climate Change, edited by: Solomon, S., Qin, D., Manning, M., Chen, Z., Marquis, M., Averyt, K. B., Tignor, M., and Miller, H. L., Cambridge University Press, Cambridge, UK, and New York, NY, USA, 2007.

North Greenland Ice Core Project members: High-resolution climate record of Northern Hemisphere climate extending into the last interglacial period, Nature, 431, 147-151, 2004.

Oppo, D. W., McManus, J. F., and Cullen, J. L.: Evolution and demise of the Last Interglacial warmth in the subpolar North Atlantic, Quaternary Sci. Rev., 25, 3268-3277, 2006.

Pausata, F. S. R., Li, C., Wettstein, J. J., Kageyama, M., and Nisancioglu, K. H.: The key role of topography in altering North Atlantic atmospheric circulation during the last glacial period, Clim. Past, 7, 1089-1101, doi:10.5194/cp-7-1089-2011, 2011.

Peltier, W. R: Global glacial isostasy and the surface of the ice-age Earth: the ICE-5G (VM2) model and GRACE, Annu. Rev Earth Planet. Sci., 32, 111-149, 2004.

Petit, J., Jouzel., J., Raynaud, D., Barkov, N., Barnola, J.-M., Basile, I., Bender, M., Chappellaz, J., Davis, M., Delaygue, G., Delmotte, M., Kotlyakov, V., Legrand, M., Lipenkov, V., Lorius, C., Pépin, L., Ritz, C., Saltzman, E., and Stievenard, M.: Climate and atmospheric history of the past 420,000 years from the Vostok ice core, Nature, 399, 429-436, 1999.

Rasmussen, T. L., Thomsen, E., Kuijpers, A., and Wastegård, S.: Late warming and early cooling of the sea surface in the Nordic seas during MIS 5e (Eemian Interglacial), Quaternary Sci. Rev., 22, 809-821, 2003.

Renssen, H., Seppä, H., Heiri, O. Roche, D. M., Goosse, H., and Fichefet, T.: The spatial and temporal complexity of the Holocene thermal maximum, Nat. Geosci., 411-414, 2009.

Risebrobakken, B., Dokken, T., and Jansen, E.: Extent and variability of the Meridional Atlantic Circulation in the Eastern Nordic Seas during Marine Isotope Stage 5 and its influence on the inception of the last glacial, in: The Nordic Seas: an Integrated Perspective, edited by: Drange, H., Dokken, T., Furevik, T., Gerdes, R., and Berger, W. H., Climate Variability in the Nordic Seas, AGU Monograph, 20, 2005.

Risebrobakken, B., Balbon, E., Dokken, T., Jansen, E., Kissel, C., Labeyrie, L., Richter, T., and Senneset, L.: The penultimate deglaciation: high-resolution paleoceanographic evidence from a north-south transect along the eastern Nordic Seas, Earth Planet. Sc. Lett., 241, 505-516, 2006.

Schilt, A., Baumgartner, M., Blunier, T., Schwander, J., Spahni, R., Fischer, H., and Stocker, T. F.: Glacial-interglacial and millennial-scale variations in the atmospheric nitrous oxide concentration during the last 800,000 years, Quaternary Sci. Rev., 29, 182-192, 2010.

Taylor, K. E., Stouffer, R. J., and Meehl, G. A.: An overview of CMIP5 and the experiment design, B. Am. Meteorol. Soc., 93, 485-498, 2012.

Telford, R. J., Li, C., and Kucera, M.: Mismatch between the depth habitat of planktonic foraminifera and the calibration depth of SST transfer functions may bias reconstructions, Clim. Past, 9, 859-870, doi:10.5194/cp-9-859-2013, 2013.

Turney, C. S. and Jones, R. T.: Does the Agulhas Current amplify global temperatures during super-interglacials?, J. Quaternary Sci., 25, 839-843, 2010.

Van Nieuwenhove, N., Bauch, H. A., Eynaud, F., Kandiano, E., Cortijo, E., and Turon, J.-L.: Evidence for delayed poleward expansion of North Atlantic surface waters during the last interglacial (MIS 5e), Quaternary Sci. Rev., 30, 934-946, 2011. 
Vertenstein, M., Craig, T., Middleton, A., Feddema, D., and Fischer, C.: CESM1.0.4 User's Guide, available at: http://www.cesm.ucar.edu/models/cesm1.0/cesm/cesm_doc_1_ 0_4/book1.html (last access: 2012), 2012.

Yin, Q- Z.., and Berger, A.: Individual contribution of insolation and $\mathrm{CO}_{2}$ to the interglacial climates of the past 800,000 years, Clim. Dyn., 38, 709-724, doi:10.1007/s00382-011-1013-5, 2012.
Zhang, Z. S., Nisancioglu, K., Bentsen, M., Tjiputra, J., Bethke, I., Yan, Q., Risebrobakken, B., Andersson, C., and Jansen, E.: Pre-industrial and mid-Pliocene simulations with NorESM-L, Geosci. Model Dev., 5, 523-533, doi:10.5194/gmd-5-523-2012, 2012. 